\title{
Assessing the Different Types of Thermoluminescence Badges on Harshaw 6600 Plus Reader
}

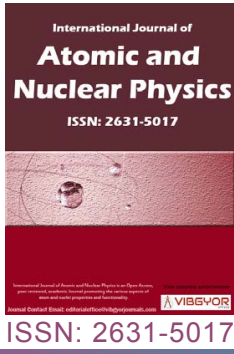

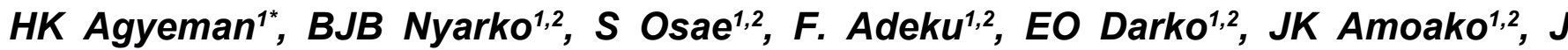
Owusu-Banahene ${ }^{1,2}$, S Inkoom 1,2, DF Charles', BK Agyeman', P Manteaw', E Amoatey', GO Aseidu', P Appiah', BD Gbekoe', P Asante ${ }^{1}$ and EM Abadoo'
\end{abstract}

${ }^{1}$ Radiation Protection Institute, Ghana Atomic Energy Commission, Ghana

${ }^{2}$ Graduate School of Nuclear and Allied Sciences, University of Ghana, Atomic Campus, Ghana

\begin{abstract}
Radiation dosimetry is defined as the measurement, usually, of the absorbed dose, or other relevant quantities like KERMA, exposure or equivalent dose, which is produced due to the interaction of the ionizing radiation with a material. That measurement can be achieved using a dosimeter. A dosimeter with its reader is called a dosimetry system.

The TLD reader system is used to process a worn TLD dosimeter. The reader automatically heats the TL material. A photo multiplier measures the TL-light released during the heating of the material from room temperature up to a maximum of $\left(250-400^{\circ} \mathrm{C}\right)$ depending on the system.

Personal dosimeters should be calibrated in terms of operational quantities for individual monitoring of external exposure (i.e. the personal dose equivalent HP (10) for strongly penetrating radiation and HP (0.07) for weakly penetrating radiation).

Personal dosimeters should be irradiated on the ISO water slab phantom $30 \mathrm{~cm} \times 30 \mathrm{~cm} \times 15 \mathrm{~cm}$ that provides an approximation of the backscatter conditions of the human body.

The purpose for calibrating TLD Cards is to ensure that all cards in a system will give virtually the same response to a given radiation exposure. Because of natural variations in TL material responsiveness and the physical mass of manufactured TL chips, there is a variation in response of as much as $30 \%$ (based on 3 sigma) from the mean in a population of dosimeters. The calibration factor for dosimeters is called the Element Correction Coefficient (ECC). The ECC is used as a multiplier with the Reader output (in Nano Coulombs) to make the response of each dosimeter comparable to the average response of a designated group of dosimeters maintained as Calibration Dosimeters.
\end{abstract}

\section{Keywords}

Thermoluminescence dosimeter badge (TLD), Calibration, Exposure, Radiation dosimetry, Absorb dose

*Corresponding author: HK Agyeman, Radiation Protection Institute, Ghana Atomic Energy Commission, P. O. Box LG 80, Legon-Accra, Ghana

Accepted: December 19, 2019; Published: December 21, 2019

Copyright: (c) 2019 Agyeman HK, et al. This is an open-access article distributed under the terms of the Creative Commons Attribution License, which permits unrestricted use, distribution, and reproduction in any medium, provided the original author and source are credited.

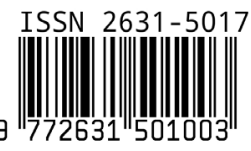

Agyeman et al. Int J At Nucl Phys 2019, 4:016 


\section{Introduction}

The TLD badge comprises of a lithium fluoride chip/crystal which is doped with titanium and magnesium ( $\mathrm{LiF}: \mathrm{Ti}, \mathrm{Mg}$ ) and placed in a holder that incorporates a filter system [1].

A TLD badge does not provide protection but detects and absorbs radiation that you have been exposed to. The badge will detect high energy beta, gamma or $\mathrm{x}$-ray radiation. Dosimeters cannot detect low energy beta radiation from some isotopes, including carbon-14, tritium and sulphur-35. The TLD is used to monitor the Personal dose equivalent at a depth of $0.07 \mathrm{~mm}$ on the body (Skin dose) and the Personal dose equivalent at a depth of 10 $\mathrm{mm}$ on the body (Deep dose) received by all occupationally exposed workers (OEWs) [1,2] (Figure 1 and Figure 2).

In actual fact, the TLD Badge does not protect the occupational worker from the effects of radiation, neither does it act as a magnet to collect the radiation dose, but rather it absorbs the radiation in the field of work [3]. Once you are exposed, the Health Physicist uses your TLD to estimate the amount of radiation you are exposed to in the course of your work. The results obtained after the evaluation of the TLD card with the Harshaw 6600 PLUS TLD Reader will help you to know how much radiation you are exposed to during the course of your work. This will help estimate your potential risks due to exposure to radiation [4].

\section{Advantage of Harshaw TLD model 6600 plus}

Harshaw TLD Model 6600 Plus Features, Benefits and Technical Specifications Features and Benefits Based on proven worldwide success of the Model 6600 One Dosimetry solution, not multiple readers, for: Whole body betas, photons and neutrons with a single dosimeter - extremity - environmental Significant labor and cost savings with enhanced Dosimetry performance. No requirement for a separate extremity system Significant time savings with automatic calibration capabilities Built-in automatic dosimeter calibration capability - Lets you decide when to recalibrate - Puts you in control of your system Non-proprietary technology Exceeds IEC, ISO and ANSI performance requirements Extensive builtin automatic QC tests \& high MTBF Flat Panel display and touchscreen operation TLD does not have the disadvantages of OSL materials and technologies Dosimeters TL dosimeter cards are available in varying forms and materials types [5]. TL material may be either standard or high sensitivity LiF material. The high sensitivity material allows extended monitoring periods of up to 6 months. LiF has excellent energy response

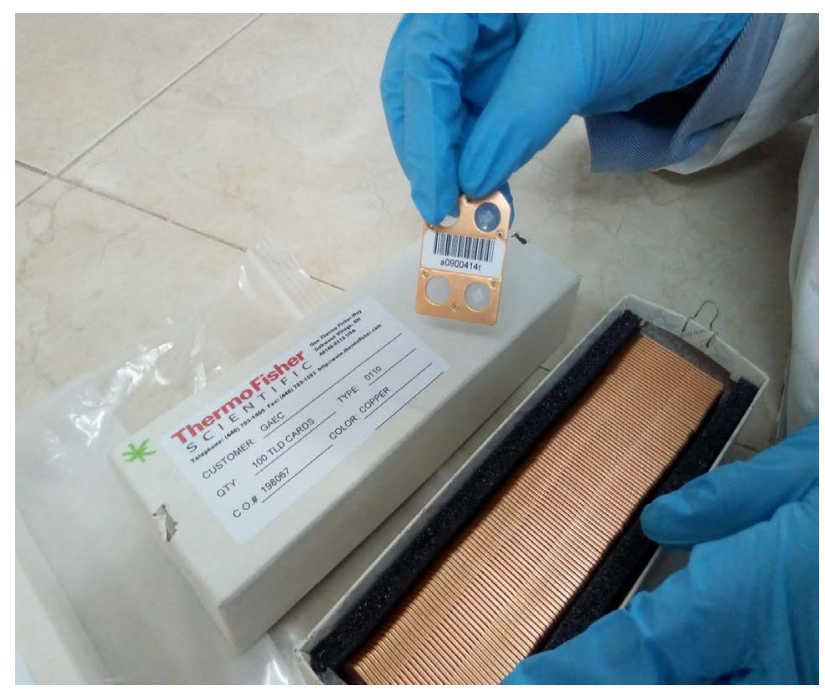

Figure 1: Picture of a Thermoluminescent Dosimeters (TLD) badge comprising of a lithium fluoride chip/crystal which is doped with titanium and magnesium (LiF: Ti, Mg).

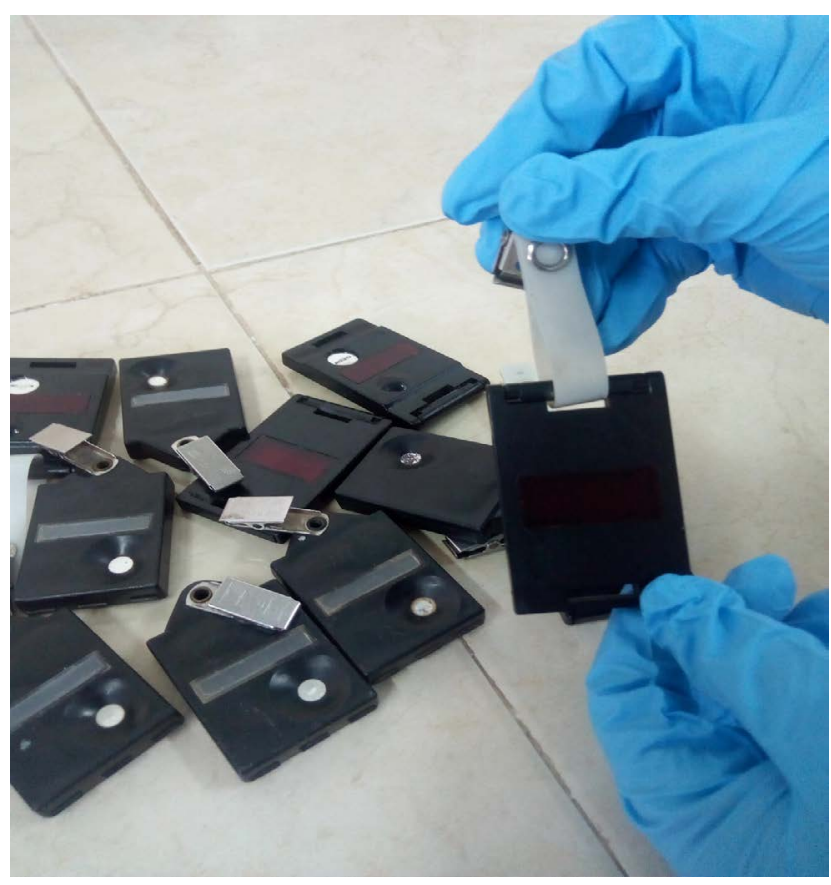

Figure 2: Picture of a Thermoluminescent Dosimeters (TLD) badge comprising of a lithium fluoride chip/ crystal which is doped with titanium and magnesium (LiF: Ti, Mg), placed in a holder that incorporates a filter system. 
due to being near tissue equivalent, unlike $\mathrm{Al}_{2} \mathrm{O}_{3}$ or $\mathrm{CaSO}_{4}$. For whole body personnel and environmental monitoring, the sensitive elements are securely fixed to sturdy aluminum cards with a barcode to ensure complete chain of custody.

\section{Advantage of instadose}

Active Dosimetry Systems, Active Radiation Dosimeters or Electronic Personal Dosimeters have the advantage of providing a direct display of the accumulated radiation dose and dose rate to the wearer as well audible and visual indication of the dose rate level. Smaller than a flash drive, this dosimeter provides an instant read-out. Small Lightweight Design. USB Compatible Detector. It can be used in Dental, Animal Health, Healthcare and Medical Facilities [3].

\section{Advantage of optically stimulated lumines- cence (OSL)}

The combination of OSL and $\mathrm{Al}_{2} \mathrm{O}_{3}$ : has many advantages: high sensitivity, improving low dose precision and enabling thin layer dosimeters; possibility to re-analysis the dosimeters as very little of the signal is lost in each read. In physics, optically stimulated luminescence (OSL) is a method for measuring doses from ionizing radiation $[6,7]$. Radiation Dosimetry, which is the measurement of accumulated radiation dose in the tissues of health care, nuclear, research and other workers, as well as in building materials in regions of nuclear disaster. Optically stimulated luminescence (OSL) is a process in which a pre-irradiated (exposed to ionizing radiation) material when subjected to an appropriate optical stimulation, emits a light signal proportional to the absorbed dose. The wavelength of the emitted light is the characteristic of the OSL material.

\section{Types of TLD Bagdes}

1. Chest badge: It is used for estimation of the whole-body dose, worn at the chest level.

2. Wrist badge: It has a strap to be worn around wrist. It is used to estimate the dose to hands and to the forearms when they are likely to be selectively exposed.

3. Finger ring: The TLD chip is housed in plastic ring and worn on the dominant finger. It measures extremity dose (fingers, hands).

Every occupationally exposed workers who op- erate $\mathrm{x}$-ray machines, fluoroscopy units, certain sealed and unsealed radioisotopes or who are exposed to other sources of gamma or high energy beta radiation are generally required to wear one or more dosimeters.

New institutions working with radiation sources or radiation emitting devices must apply for TLD badges providing the names and positions of the personnel to be monitored. They also must complete a personnel data form by providing all the required details. Once the Radiation Protection Institute reviews the application, a dosimeter will be issued if needed.

The TLD badge must be worn on the front of the upper torso of the body, between the shoulders and the waist $[7,8]$. TLD badge should be worn for a period of one (1) month and shall not exceed three (3) months, after which it is to be sent to the service provider, Radiation Protection Institute (RPI), for evaluation and assessment.

The primary occupational whole body dose limit is $20 \mathrm{mSv}$ per year averaged over a five-year period and should not exceed $50 \mathrm{mSv}$ in any single year.

The annual equivalent dose limit for the skin, the hands and feet (extremities) is $500 \mathrm{mSv}$ and for the lens of the eye is $150 \mathrm{mSv}$.

When an occupationally exposed worker being monitored leaves the facility or changes work locations, please notify the Health Physics and Instrumentation Centre (HPIC) of the Radiation Protection Institute (RPI).

\section{Materials and Methods}

\section{Materials}

Harshaw 6600 plus TLD reader: For this project, the Harshaw TLD (Model 6600 PLUS) located at the Radiation Protection Institute is the reader used for estimating whole body and extremity effective doses recorded by the TLDs. A non-contact heating system is used which utilizes a stream of hot nitrogen gas. The Reader is interfaced to a computer where all measured data can also be displayed, stored and printed $[2,6]$. A hand held scanner is used to identify each TLD card before reading (Figure 3 and Figure 4).

Thermoluminescent dosimeter: The most widely used material is the LiF with added magnesium and titanium. TLD-100 is LiF: $\mathrm{Mg}$, Ti which 


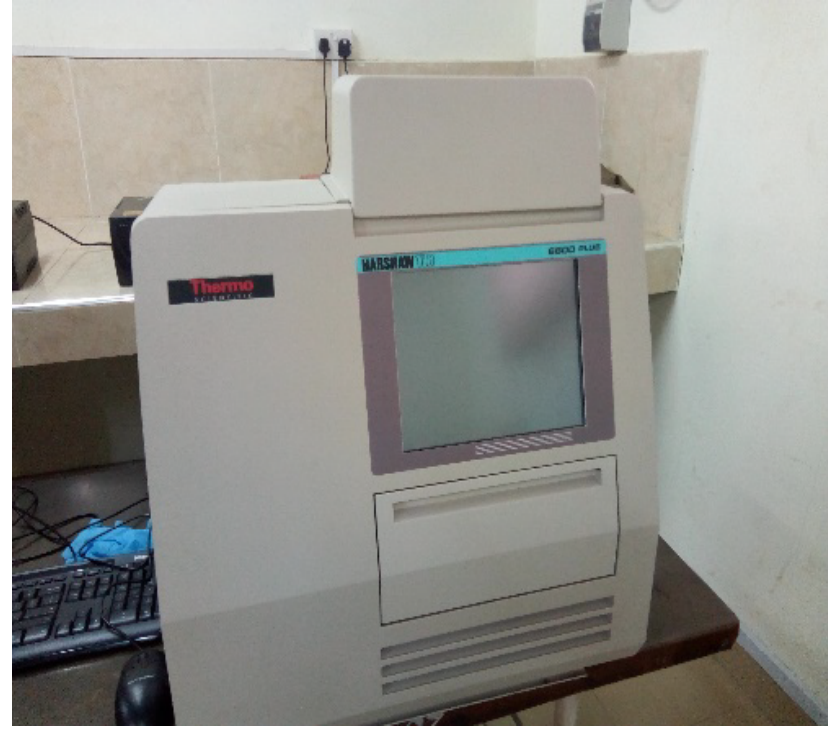

Figure 3: Picture of Harshaw 6600 plus TLD reader.

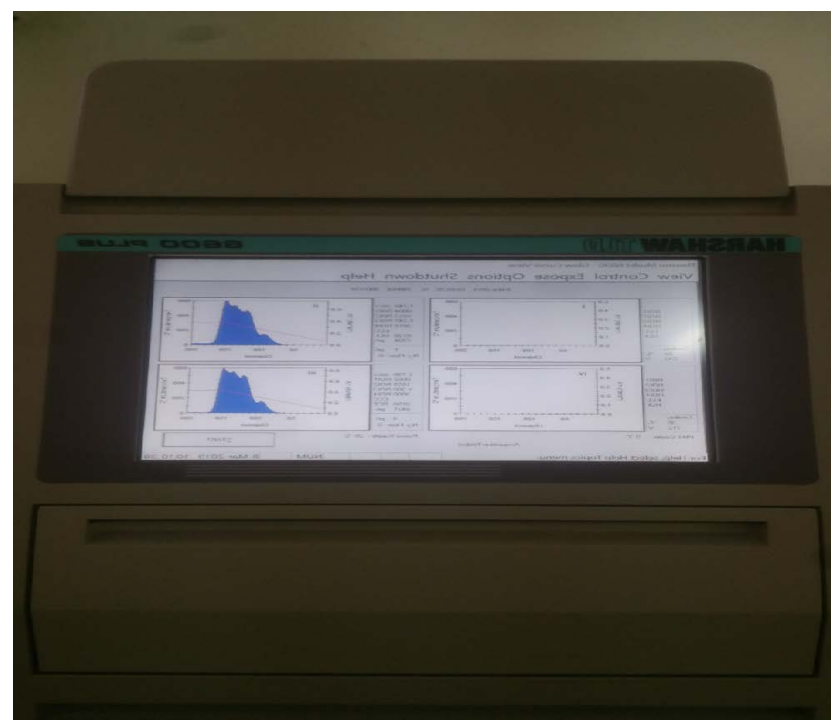

Figure 4: Picture of Harshaw TLD 6600 plus reader showing some glow curve.

consists of $92.5 \%$ of $\mathrm{Li}-7$ and $7.5 \%$ of $\mathrm{Li}-6$. Each card consists of four/two chips. In this project, five hundred (500) new two elements TLD 100 were used. The TLD cards are fixed in their holders which consist of two aluminum filters of different thicknesses; $0.07 \mathrm{~mm}$ (for skin dose measurements) and $10 \mathrm{~mm}$ (for deep dose measurements). One corner of the TLD card is notched to make sure it is placed correctly in the Reader holder system. The Reader holder system protects the cards from the environment and keeps the filtration media which attenuate different types of radiation in order to ensure selective en-

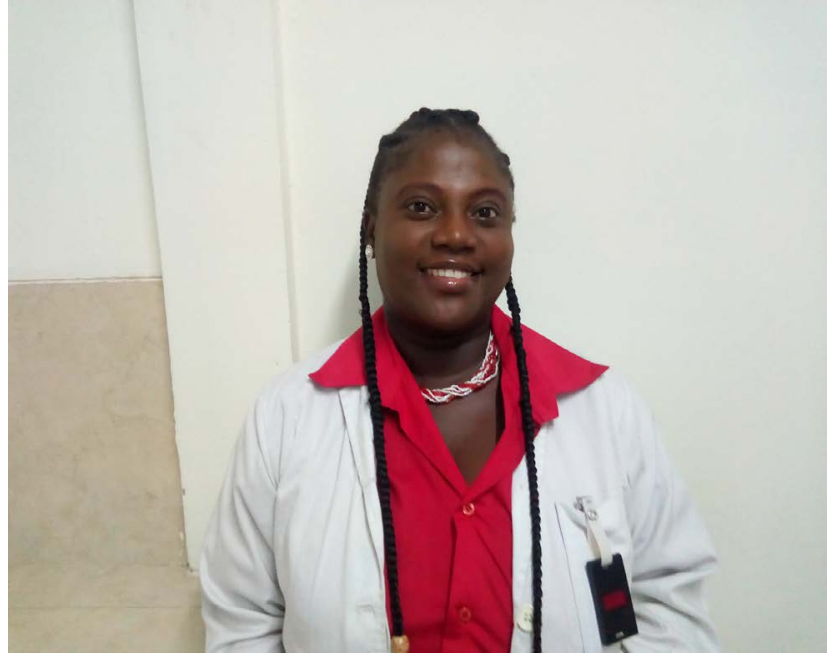

Figure 5: Picture of a technologist wear her Thermoluminescent Dosimeter (TLD) badge.

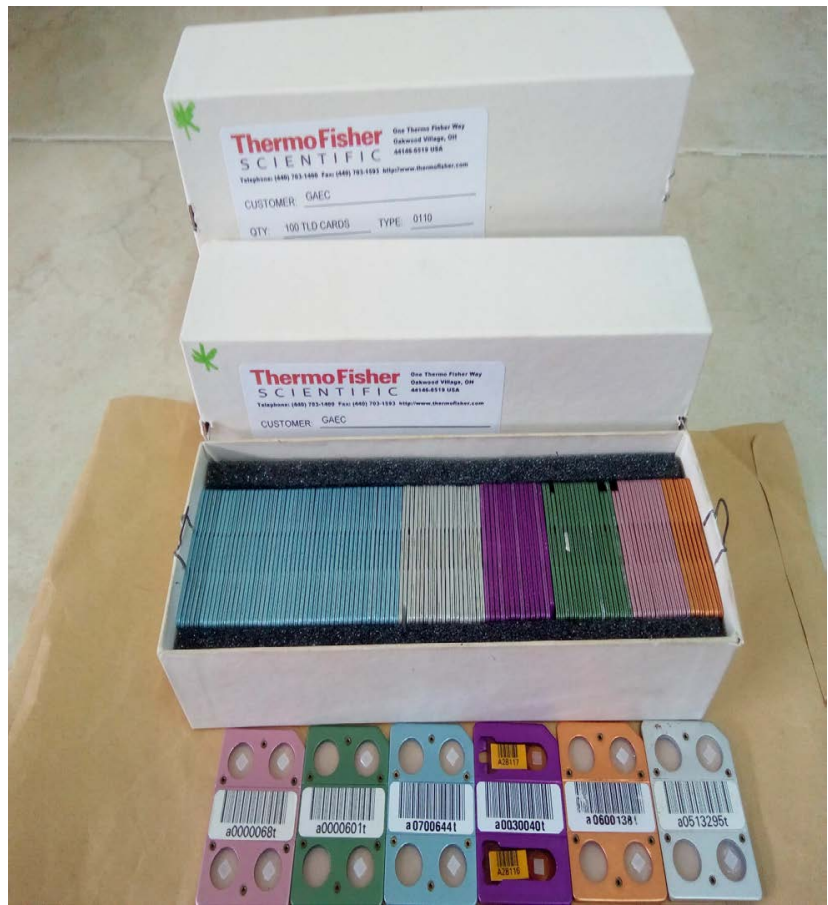

Figure 6: Pictures different colors of Thermoluminescent Dosimeters (TLD) badges with different bar codes.

trapments of the TLD-100 [3,9] (Figure 5, Figure 6 and Figure 7).

Apart from the chips, each card has a unique barcode.

Cs-137 calibration source: The Air kerma rate $\left(k_{\text {air }}\right)$ of the Cs-137 source used in the Secondary Standards Dosimetry Laboratory for the calibration was 1. $\mathrm{mSv} / \mathrm{hr}[9,10]$. 


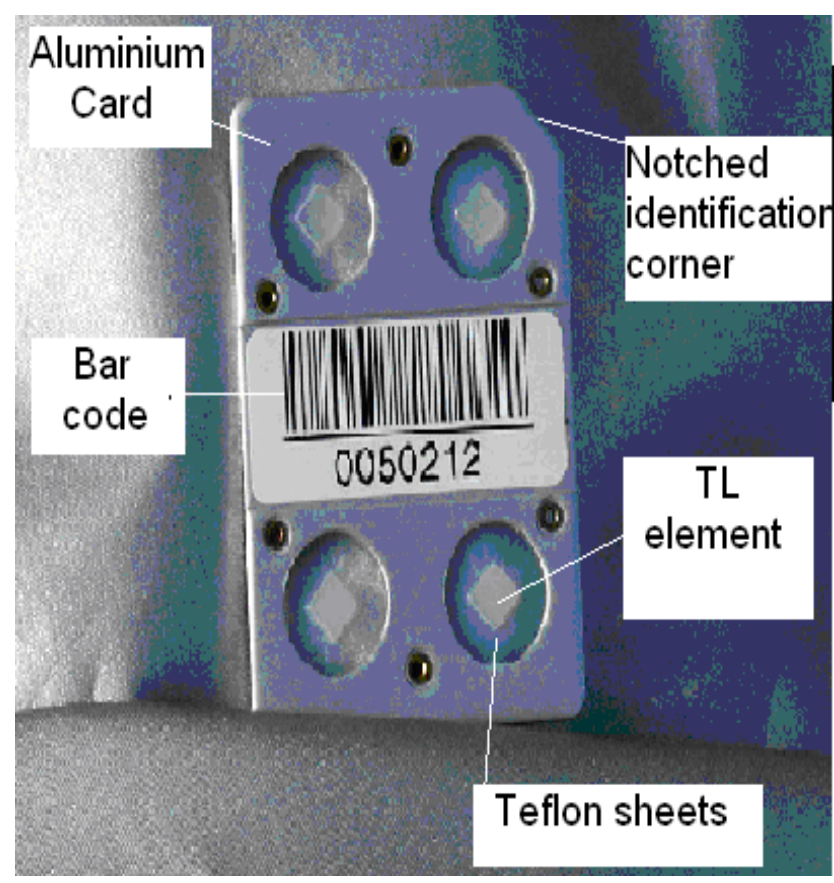

Figure 7: The integral part of a Thermoluminescent Dosimeter (TLD) badge.

\section{Methodology}

Calibration of Harshaw TLD 6600 plus reader: Full calibration of the Harshaw Model TLD 6600 PLUS required calibrating both the Reader and all the TLD cards used in the system [5]. Before setting up the system it was important that the following directions and steps were carefully followed;

(i) Dosimeter Preparation.

(ii) Generation of Calibration Dosimeters.

(iii) Calibration of Reader.

(iv) Calibration of new TLD Field cards.

\section{Dosimeter Preparation}

Before beginning any calibration procedures, the new dosimeters acquired were sensitized. The dosimeters were annealed and irradiated for a minimum of three cycles to sensitize the TLD centers [11]. The next step was to set a fixed fade time between irradiation and readout for all dosimeters. Any length of time that suits the operation was acceptable, but it had to be consistent from one time to the next. The Procedure was as follows:

a. The Reader annealed the Dosimeters to clear them of all residual exposure.

b. After annealing, the dosimeters were stored in a shield enclosure for one hour at a temperature below $30^{\circ} \mathrm{C}$ before irradiation. c. The dosimeters were then exposed to a known radiation source (normally Cs 137 ) within two hours after annealing.

d. The dosimeters were again stored in a shielded enclosure for one hour at a temperature below $30{ }^{\circ} \mathrm{C}$.

e. The dosimeters were read for calibration purposes.

\section{Generation of Calibration Dosimeters}

This procedure established the Element Correction Co-efficient (ECC) of these cards without reference to the Reader [12-14]. These cards were retained for subsequent re-calibration of the Reader. Below were the procedures in generating Calibration Dosimeters:

1. The cards were loaded into the reader and set the Reader function on the Result Screen to a "Remote Operation".

2. From the WIN REMS main menu on PC, "Data Acquisition" was selected. From the Data Acquisition Menu, "Time Temperature Profile (TTP)" was also selected.

3. The TTP was set to the required condition and return to the Data Acquisition Menu.

4. From the Data Acquisition Menu, "Acquisition setup" was selected. The Acquisition setup was set to the required conditions.

5. "Read Cards" was selected and then "Enter", this brought up the Read Cards Screen. A unique group Number and the appropriate TTP number was entered.

6. "Function Field" was selected. From the pop-up menu "Generate Cal. Dosimeters" was selected.

7. "Start Reading" was selected and the comment prompt was responded, then "Start". The Reader began to read the Cards and display the data in accordance with both the setting in the TTP and Acquisition setup screen.

8. After completing the Reading process, "QA Procedure" was selected from the Main Menu; then "Generate Calibration Cards" was selected. Then the same Group number assigned earlier on and an acceptable ECC range for each position (ii and iii for a two-element position cards) were entered and the ECC calculations was initiated.

9. When the calculation process was completed, 
the report was printed to obtain a list of calibration cards.

\section{Calibration of TLD Reader}

The calibration Dosimeters generated was used to establish the Reader Calibration Factor (RCF) for each Time-Temperature Profile (TTP) through the procedures below:

1. Four (4) of the calibration cards were annealed and exposed as before to 1000 uSv of Cs-137 source to the required conditions and were loaded into the Reader.

2. The Function Field was set to "Remote Operation" on the Reader Results Screen which transferred control of Reader to the REMS PC.

3. From the WinREMS Main Menu on the Screen "Data Acquisition" was selected from the Data Acquisition Menu, then, "Acquisition Setup" Screen. The Acquisition setup screen was set to the required conditions before returning to the Data Acquisition Menu.

4. A unique Group Number was entered and the number of the TTP being calibrated which has been set to the required conditions and the cards were read.

5. On the Reader Calibration Screen, the Nominal Irradiation Value (1000 uSv) to which the cards were exposed was set. Also enter the
TTP number, the Group number and the Calibration Units (mGy).

6. "Start Reader Calibration" was selected to bring the "Calibrate Reader" Statistics Screen into view. The new RCFs were applied and a report with the new calibration values was generated.

\section{Calibration of new field TLD cards}

Below are the procedures for generating ECCs for the field TLD cards:

1. The cards were prepared and exposed to 1000 uSv of Cs-137. The cards were loaded into the reader and read after entering a unique group Number and the TTP number.

2. Previously selected.

3. On the Card Calibration screen, the following data was entered; the acceptable ECC Range for each element position $(0.77 ; 1.43)$, recommended for field cards the nominal irradiation value to which the dosimeters were exposed.

4. "Start Card Calibration" was entered and the ECCs were calculated and the results.

5. Stored in the ECC Database to be used anytime the dosimeters are read.

\section{Results and Discussion}

The calibration factor for dosimeters called Element Correction Coefficient (ECC) is used as

\section{GOLDEN CARDS}

GENERATE CALIBRATION DOSIMETERS REPORT

Page 1 of 2

Calibration Results

Date Time

$6 / 27 / 2018$

$* 6 / 27 / 2018$

$6 / 27 / 2018$

*6/27/2018

$6 / 27 / 2018$

$6 / 27 / 2018$
10: $19: 14$

10: $20: 06$

10: $20: 57$

10: $21: 50$

10: $22: 49$

$10: 23: 42$
TTP Dosimeter ID

0700111

0700172

0700224

0700028

0700163

0700305
Element Correction Coeficient

(i)

(ii)

(iii)

$1.045 \quad .9772$

$1.072 \quad .8629$

$1.046 \quad .9820$

$.9892 \quad 1.127$

$.9535 \quad .9829$

$.9635 \quad 1.063$
(ECC)

(iv) 
*not used. in the calibration process

Reading Statistics
Calibrating : $\quad$ TTP2018 (TTP \#1)
Instrument ID : PDL4500

$\begin{array}{ll}\text { Irradiation Value : } & 1000 \\ \text { Total Readings : } & 4 \\ \text { Accepted Readings : } & 4 \\ \text { Rejected Readings : } & 0\end{array}$

Mean :

59.08

Pending RCF Value :

Differences (\%) :

PMT Noise (1 Readings) :

Mean:

.0560

.0567

.0133

.0058

Standard Deviation (\%) :

Reference Light (1 Readings) :

Mean:

171.0

171.2

196.5

197.3

Standard Deviation (\%) :

Figure 9: Results showing reader calibration report.

a multiplier with the reader output (charge in Nano coulombs) to make the response of each dosimeter comparable to the average response of a group of calibration dosimeters $[15,16]$. The Reader Calibration Factor (RCF) is then used to convert the raw charge data from the Photomultiplier Tubes (in Nano coulombs) to the Dose (D) on the TLD Card.

The two factors are applied according to the following formula to evaluate the Dose (D);

$$
\text { Dose }=E C C \times \text { charge } / R C F \text {. }
$$

Four (4) TLDs were used as golden cards to establish the Reader Calibration Factor (RCF). The ECC range for calibrating the reader was between 0.9 and 1.1 allowing for only $\pm 10 \%$ deviation.

The RCFs for elements ii and iii were established as 0.059079 and 0.047272 (Figure 8, Figure 9 and Figure 10). 


\begin{tabular}{|c|c|c|c|c|c|c|}
\hline \multicolumn{2}{|c|}{ DOSIMETER CALIBRATION } & \multicolumn{2}{|c|}{ REPORT } & \multicolumn{3}{|r|}{ Page i } \\
\hline Calibration & Results & & & Element Corred & ection & Coeficient (ECC) \\
\hline $\begin{array}{l}\text { Date } \\
7 / 26 / 2018\end{array}$ & Time & TTP & Dosimeter ID & (i) & (ii) & (iii) (iv) \\
\hline $\begin{array}{r}7 / 26 / 2018 \\
\times \quad 7 / 26 / 2018\end{array}$ & $09: 44: 05$ & 1 & 0700814 & & .8638 & 1.306 \\
\hline $\begin{array}{l}* \quad 7 / 26 / 2018 \\
7 / 26 / 2018\end{array}$ & $09: 44: 57$ & 1 & 0700054 & & .9468 & 1.506 \\
\hline $\begin{array}{r}7 / 26 / 2018 \\
* \quad 7 / 26 / 2018\end{array}$ & $09: 45: 48$ & 1 & 0700030 & & .8533 & 1.263 \\
\hline $\begin{array}{l}\text { * } 7 / 26 / 2018 \\
\text { * } 7 / 26 / 2018\end{array}$ & $09: 46: 40$ & 1 & 0002808 & & .9913 & 1.621 \\
\hline $\begin{array}{l}\text { * } 7 / 26 / 2018 \\
* 7 / 26 / 2018\end{array}$ & $09: 47: 35$ & 1 & 0700722 & & .8375 & 1.543 \\
\hline $\begin{array}{r}* 7 / 26 / 2018 \\
7 / 26 / 2018\end{array}$ & $\begin{array}{l}09: 48: 25 \\
09: 49: 45\end{array}$ & 1 & 0700835 & & 1.007 & 1.591 \\
\hline $\begin{array}{l}7 / 26 / 2018 \\
7 / 26 / 2018\end{array}$ & $\begin{array}{l}09: 49: 45 \\
09: 50: 40\end{array}$ & 1 & 0600311 & & .8735 & 1.300 \\
\hline $\begin{array}{r}7 / 26 / 2018 \\
\times \quad 7 / 26 / 2018\end{array}$ & $\begin{array}{l}09: 50: 40 \\
09: 51: 38\end{array}$ & 1 & 0600105 & & .8246 & 1.352 \\
\hline $\begin{aligned} * 7 / 26 / 2018 \\
7 / 26 / 2018\end{aligned}$ & $\begin{array}{l}09: 51: 38 \\
09: 52: 39\end{array}$ & 1 & 0600198 & & .8232 & 1.450 \\
\hline $7 / 26 / 2018$ & $\begin{array}{l}09: 52: 39 \\
09: 56: 06\end{array}$ & 1 & 0600400 & & .8748 & 1.402 \\
\hline $7 / 26 / 2018$ & $\begin{array}{l}09: 56: 06 \\
09: 59: 30\end{array}$ & 1 & 0600104 & & .7253 & 1.133 \\
\hline $7 / 26 / 2018$ & $\begin{array}{l}09: 59: 30 \\
10: 00: 37\end{array}$ & 1 & 0600277 & & .8924 & 1.237 \\
\hline * $7 / 26 / 2018$ & $\begin{array}{l}10: 00: 37 \\
10: 01: 30\end{array}$ & 1 & 0600144 & & .9058 & 1. 334 \\
\hline $7 / 26 / 2018$ & $\begin{array}{l}10: 01: 30 \\
10: 12: 59\end{array}$ & 1 & 0600459 & & 1.316 & 2.020 \\
\hline $7 / 26 / 2018$ & $\begin{array}{l}10: 12: 59 \\
10: 14: 03\end{array}$ & 1 & 0600265 & & .8351 & 1.259 \\
\hline $7 / 26 / 2018$ & $\begin{array}{l}10: 14: 03 \\
10: 14: 52\end{array}$ & 1 & 0600459 & & .9155 & 1.313 \\
\hline $7 / 26 / 2018$ & $\begin{array}{l}10: 14: 52 \\
10: 15: 43\end{array}$ & 1 & 0600134 & & .8585 & 1.290 \\
\hline $7 / 26 / 2018$ & $\begin{array}{l}10: 15: 43 \\
10: 16: 41\end{array}$ & 1 & 0600091 & & .8436 & 1.315 \\
\hline $7 / 26 / 2018$ & $\begin{array}{l}10: 16: 41 \\
10: 17: 36\end{array}$ & 1 & 0600292 & & .9036 & 1.341 \\
\hline * $7 / 26 / 2018$ & $\begin{array}{l}10: 17: 36 \\
10: 18: 32\end{array}$ & 1 & 0600437 & & .8196 & 1.385 \\
\hline $7 / 26 / 2018$ & $\begin{array}{l}10: 18: 32 \\
10: 19: 38\end{array}$ & 1 & 0700936 & & .9423 & 1.620 \\
\hline $7 / 26 / 2018$ & $\begin{array}{l}10: 19: 38 \\
10: 20: 33\end{array}$ & 1 & 0600145 & & .8921 & 1.393 \\
\hline $7 / 26 / 2018$ & $\begin{array}{l}10: 20: 33 \\
10: 21: 33\end{array}$ & 1 & 0600290 & & .8601 & 1.375 \\
\hline $7 / 26 / 2018$ & $\begin{array}{l}10: 21: 33 \\
10: 24: 22\end{array}$ & 1 & 0600141 & & .9024 & 1.343 \\
\hline $7 / 26 / 2018$ & $\begin{array}{l}10: 24: 22 \\
10: 25: 36\end{array}$ & 1 & 0600477 & & .8515 & 1.257 \\
\hline $7 / 26 / 2018$ & $\begin{array}{l}10: 25: 36 \\
10: 26: 34\end{array}$ & 1 & 0600154 & & .8480 & 1.192 \\
\hline $7 / 26 / 2018$ & $\begin{array}{l}10: 26: 34 \\
10: 27: 33\end{array}$ & 1 & 0600300 & & .8939 & 1.321 \\
\hline $7 / 26 / 2018$ & $\begin{array}{l}10: 27: 33 \\
10: 28: 33\end{array}$ & 1 & 0600214 & & .9251 & 1.313 \\
\hline $7 / 26 / 2018$ & $\begin{array}{l}10: 28: 33 \\
10: 29: 26\end{array}$ & 1 & 0600387 & & .8725 & 1.356 \\
\hline & & 1 & 0600121 & & .8686 & 1.295 \\
\hline
\end{tabular}

Figure 10: Results showing reading of field cards.

\section{References}

1. Attix FH (1986) Introduction to radiological physics \& radiation dosimetry. John Wiley \& Sons, Canada.

2. Won JL, Eun SC, Mina H, Young-Woo J, Seung-Sik H, et al. (2009) Occupational radiation doses among diagnostic radiation workers in South Korea. Radiat Prot Dosim 136: 50-55.
3. Glasgow GP, Eichling J, Yoder RC (1986) Observations on personnel dosimetry for radiotherapy personnel operating high-energy LINACS. Health Phys 50: 789795.

4. Gunduz H, Zeyrek CT, Aksu L, lask S (2004) occupational exposure to ionizing radiation in the region of Anatolia, Turkey for the period 1995-1999. Radiat 
Prot Dosimetry 108: 293-301.

5. (2002) Model 6600 Automated TLD Reader with WinREMSTM: Operator's manual. Publication No. 6600-W-0-0602-005.

6. (1996) International basic safety standards for protection against ionizing radiation and for the safety of radiation sources. International Atomic Energy Commission (IAEA), Safety Series No. 115.

7. Lee WJ, Cha ES, Ha M, Jin YW, Hwang SS, et al. (2009) Occupational radiation doses among diagnostic radiation workers in South Korea, 1996-2006. Radiat Prot Dosimetry 136: 50-55.

8. (2002) Occupational Radiation Protection. Radiation protection and safety guide, GRPB-G3: 2000.

9. Allisy A, Jennings WA, Kellerer AM, Müller JW (1993) Quantities and units in radiation protection dosimetry. Journal of the International Commission on Radiation Units and Measurements, Report 51.

10.(1990) 1990 Recommendations of the international commission on radiological protection. Ann ICRP 21: 1-3.
11.Colgan PA, Currivan L, Fenton D (2008) An assessment of annual whole-body occupational radiation exposure in Ireland. Radiat Prot Dosim 128: 12-20.

12.Ogundare FO, Balogun FA (2003) Whole-body doses of occupationally exposed female workers in Nigeria (1999-2001). J Radiol Prot 23: 201-208.

13.Bolus NE (2008) Review of common occupational hazards and safety concerns for nuclear medicine technologist. J Nucl Med Technol 36: 11-17.

14. Korir GK, Wambani JS, Korir IK (2011) Estimation of annual occupational effective doses from external ionizing radiation at medical institutions in Kenya. SA Journal of Radiology 15: 353.

15. Hasford F, Owusu-Banahene J, Amoako JK, Otoo F, Darko EO, et al. (2011) Assessment of annual wholebody occupational radiation exposure in medical practice in Ghana. Radiat Prot Dosimetry 149: 431437.

16.(2005) Radiation oncology physics: A handbook for teachers and students. IAEA, Vienna. 